Article

\title{
The Concentration of Polyunsaturated Fatty Acid in Palm Oil by Urea Complexation
}

\author{
Dwi Ardiana Setyawardhani ${ }^{1, a}$, Margono ${ }^{1, b,}$, Ardi Pratama $^{2}$, and Fermanditya Petratama ${ }^{2}$ \\ 1Chemical Engineering Department, Sebelas Maret University, Jl. Ir. Sutami 36 A Surakarta \\ 2Chemical Engineering Department, Sebelas Maret University, Jl. Ir. Sutami 36 A Surakarta \\ E-mail: adwi_ardiana@yahoo.com, bmrgono04@yahoo.com (Dwi Ardiana Setyawardhani)
}

\begin{abstract}
Linoleic acid is a Poly-Unsaturated Fatty Acid (PUFA) that corresponds to Omega 6 Fatty Acid. This is the major component of vegetable oil and very important for health. As an essential fatty acid, linoleic acid has to be obtained from foods. Consumption of omega fatty acid in the form of concentrate has more benefit than the whole oil. Fulfilling this requirement, effective method to separate PUFAs from vegetable oils is needed. One of the favorable methods is urea complexation. Palm oil was used as the fatty acids resource due to its potential feedstock in Indonesia. This aim of this research is to study the effect of urea, ethanol and free fatty acid (FFA) ratios during complexation of palm oil. This research was developed in three steps, 1) free fatty acid preparation from palm oil (saponification process), 2) crystallization of the fatty acids mixture and 3) filtration for separating the unsaturated fatty acid. Concentrated linoleic acid is obtained in the liquid phase, while the saturated fatty acid is obtained in the solid. This research resulted that the concentration of PUFA was increasing as the ratio of urea, FFA and ethanol increases.
\end{abstract}

Keywords: Poly-Unsaturated Fatty Acid, Palm Oil, Urea Complexation, Fatty Acid.

EQUILIBRIUM Volume 2 No.1 January 2018

Online at http:/ / equilibrium.ft.uns.ac.id 


\section{Introduction}

Urea complexation is a separation process for splitting saturated fatty acids from vegetable oil. There were several factors that must be considered in the process, such as crystallization temperature, complexation time, and the mole ratio of urea : fatty acid[1]-[3]. They will affect the yield and levels of unsaturated fatty acids on the concentrate product. The main objectives of this research are to obtain the optimum ratio of urea to fatty acids on the palm oil complexation.

Palm oil is a food ingredient with the main composition of triglycerides derived from palm oil, with or without chemical changes, and has been purified by the addition of vitamin A (SNI 7709: 2012). Palm oil as cooking oil contains saturated fatty acid (SFA) of $40-46 \%$ in palmitic acid, mono-unsaturated fatty acids (MUFA) of 39-45\% in oleic acid, and acid poly-unsaturated fatty acids (PUFA) of 7-11\% in linoleic acid [4].

Linoleic acid and linolenic acid are essential fatty acids that can not be synthesized by the human body. Urea complexation fractionation method is used to increase the concentration of unsaturated fatty acids, especially linoleic acid. It is a method for separating unsaturated fatty acids by crystalline formation due to the addition of urea. Urea complexation is an effective method due to the ability of producing the maximum concentration of unsaturated fatty acid for some feedstock. Both of the materials and equipment are simple and the solvent is inaccessible and environmentally friendly [5].

\section{Materials and Method}

\subsection{Materials}

Palm cooking oil were used as the source of fatty acids. Analytical grade urea $>99.5 \%$ was purchased from Merck, and $96 \%$ food grade aqueous ethanol employed for wetting agent. All were used without further purification. Commercial n-hexane, aquadest and high purity $\mathrm{KOH}, \mathrm{HCl}$ and $\mathrm{Na}_{2} \mathrm{SO}_{4}$ were used for supporting materials.

\subsection{Method}

This research was developed in three steps, 1) free fatty acid preparation from palm oil (saponification process), 2) crystallization of the fatty acids mixture and 3) filtration for separating the unsaturated fatty acid[1] as described on Fig.1.

\subsubsection{Preparation of Free Fatty Acid from Palm Oil}

Palm cooking oil was saponified using ethanol, $\mathrm{KOH}$, and aquadest to obtain fatty acids mixtures. The reaction products were mixed with $150 \mathrm{ml}$ of aquadest, and then was extracted 2 times using $300 \mathrm{ml}$ $\mathrm{n}$-hexane. The mixture was separated using separating funnel to form $\mathrm{n}$-hexane layer and water layer. The water layer was acidified using $3 \mathrm{~N} \mathrm{HCl}$ until it reached $\mathrm{pH}=1$. The fatty acid layer was reextracted using $150 \mathrm{ml}$ of $\mathrm{n}$-hexane and the water layer is removed. Slightly water content of the $\mathrm{n}$ hexane layer were removed using $\mathrm{Na}_{2} \mathrm{SO}_{4}$ as adsorbent and $\mathrm{n}$-hexane was evaporated by rotary evaporator leaving the free fatty acid.

\subsubsection{Crystallization}

The crystallization step is carried out by mixing free fatty acids with $96 \%$ urea-ethanol $(\mathrm{w} / \mathrm{v})$ solution. The mixing is carried out at $60^{\circ} \mathrm{C}$ under stirring until the mixture is homogeneous.

\subsubsection{Separation of Unsaturated Fatty Acid}

The urea complexed fraction (UCF) was separated from the solution (non-urea complexed fraction, NUCF) under filtration. NUCF (filtrate), and UCF (crystal) massively added aquadest as much as UCF and NUCF volumes were formed, then acidified using $\mathrm{HCl} 6 \mathrm{~N}$ to $\mathrm{pH} 4-5$. Extraction was carried out for 1 hour on NUCF and UCF with n-hexane as much as the initial filtrate formed to form the nhexane layer and a water layer. The $n$-hexane layer and water layer are separated by a separation funnel. 
The remaining water content in the n-hexane layer is removed with $\mathrm{Na}_{2} \mathrm{SO}_{4}$ and dusted with the rotary evaporator until fatty acid concentrate is obtained.

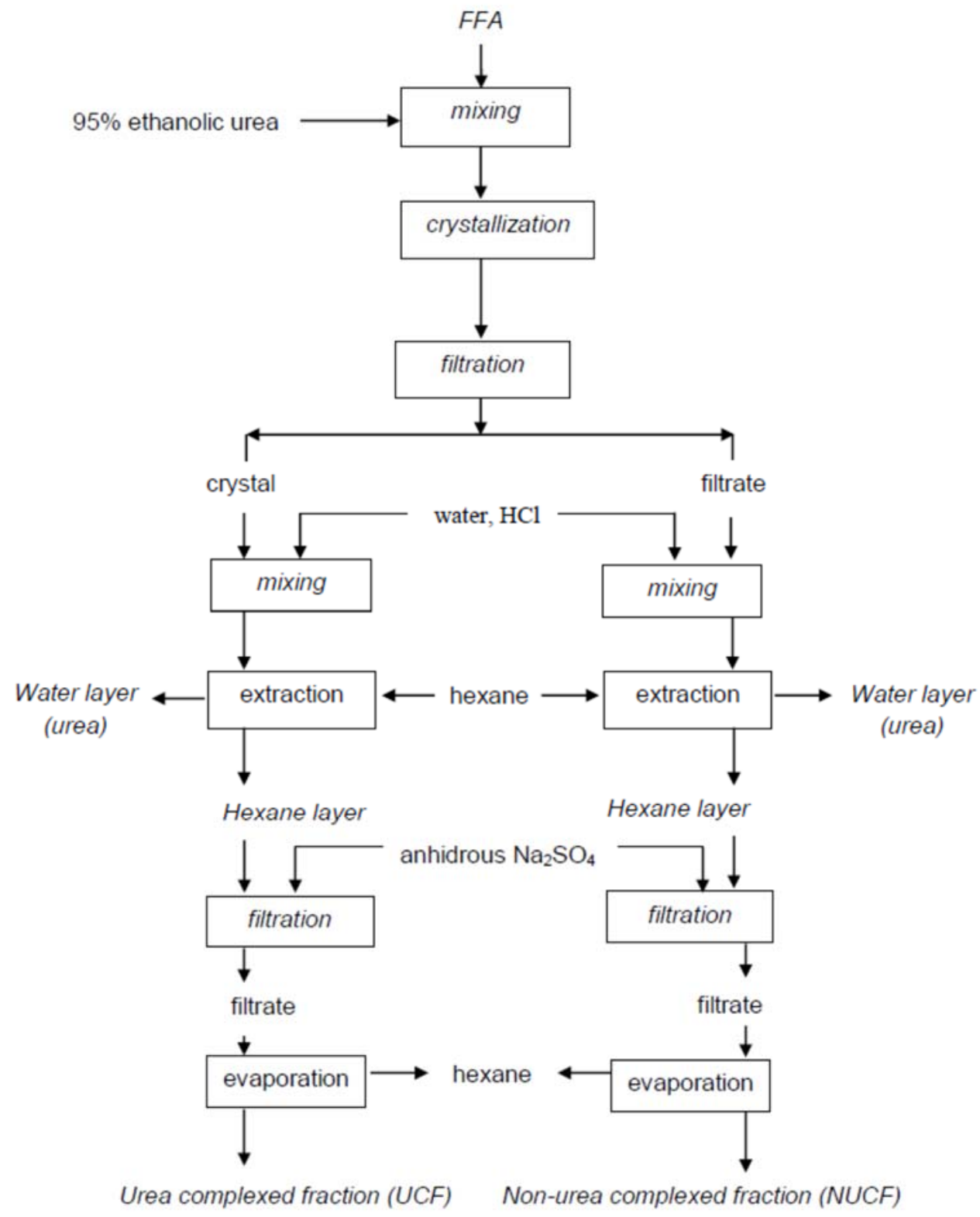

Figure 1. Urea complexation process

\subsubsection{Data Analysis}

The fatty acid concentrate obtained analyzed the concentration of unsaturated fatty acids using Gas Chromatography (GC) analysis. The concentration of unsaturated fatty acids in palm cooking oil is shown by the graph of GC analysis.

\section{Results and Discussion}

The crystals which were formed from the crystallisation stage are separated between the crystals (UCF) and the solution (NUCF). The NUCF analysis was performed with gas chromatography (GC) and the analysis result summarized the major fatty acid which is consisted of palm oil. Linoleic acid was used 
as the parameter that represented poly unsaturated fatty acids (PUFAs) and palmitic acid represented the saturated fatty acids (SFA). The results of GC analysis in the form of the major fatty acids were shown in Table 1.

Table 1. Major Fatty Acids in Palm Oil

\begin{tabular}{|c|c|c|}
\hline Component & Molecule Formula & Percentage (\%) \\
\hline Palmitic Acid & $\mathrm{C}_{15} \mathrm{H}_{31} \mathrm{COOH}(\mathrm{C} 16: 0)$ & 38 \\
\hline Linoleic Acid & $\mathrm{C}_{17} \mathrm{H}_{31} \mathrm{COOH}(\mathrm{C} 18: 2)$ & 17 \\
\hline Oleic Acid & $\mathrm{C}_{17} \mathrm{H}_{33} \mathrm{COOH}(\mathrm{C} 18: 1)$ & 45 \\
\hline
\end{tabular}

The variable studied in this research was the mole ratio of urea : free fatty acid (FFA) in complexation. The urea amount were shown in Table 2 .

Table 2. The Process Variables in the Urea Complexation

\begin{tabular}{|c|c|c|c|c|}
\hline FFA (gram) & Urea (gram) & Ethanol (mL) & Urea:Ethanol & Urea:FFA (mol) \\
\hline 7 & 20 & 100 & $1: 5$ & $12.9: 1$ \\
\hline 7 & 40 & 200 & $1: 5$ & $25.9: 1$ \\
\hline 7 & 60 & 300 & $1: 5$ & $38.8: 1$ \\
\hline
\end{tabular}

The previous investigation showed that the urea : FFA mole ratio of a UIC is 12.6: 1[6]. So, this research set the urea : FFA mole ratio was 12.9: 1 and higher. In this system, the fatty acids analyzed were that one have gone through the preparation stage of free fatty acid or FFA. Free fatty acids were analyzed containing $10 \%$ PUFA, and $90 \%$ SFA.

The result of complexation with urea: FFA 12.9: 1 increases PUFA concentration from 10\% to 96\%, and decreases SFA from 90\% to 4\% displayed in Fig. 1. The decrease in SFA concentration shows that there is a reduction of SFA molecules at the time of the complexation due to the absorption of molecules SFA into urea crystals. The reduction of the SFA concentration also occurs in the addition of 40 grams of urea. However, in the urea: FFA 38.8: 1 ratio, the SFA concentration rose to 9\%, and the PUFA concentration fell to $89 \%$. This shows that in addition to 60 grams of urea, urea crystals have reached saturation state.

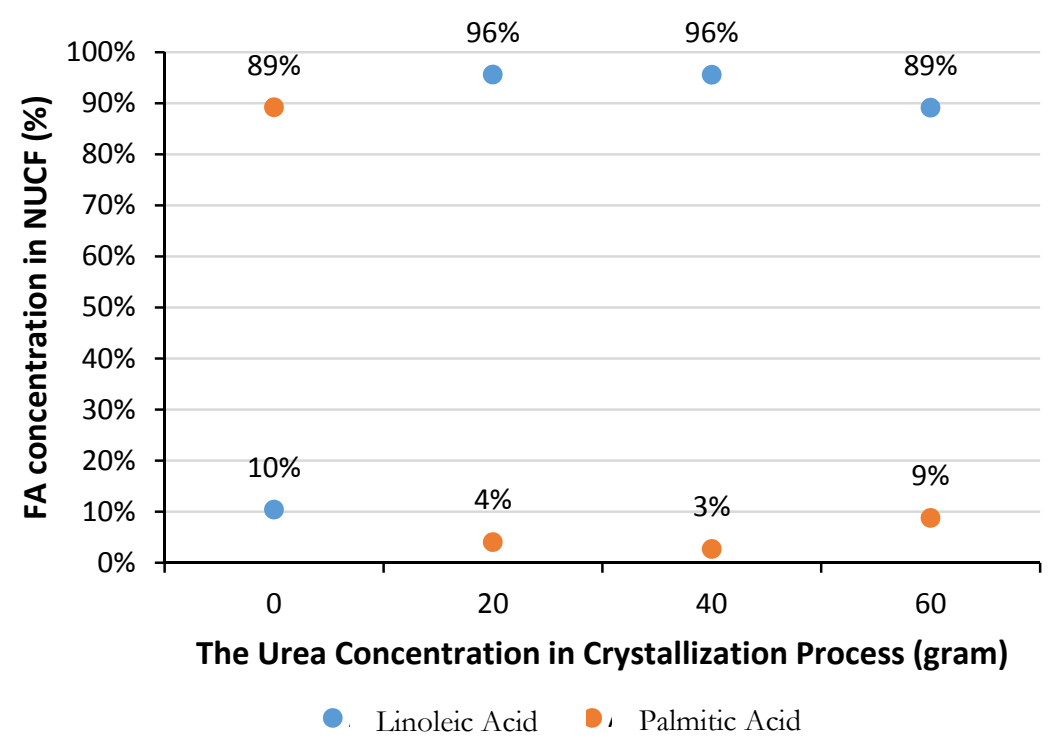

Figure 2. The SFA and PUFA concentration from various urea amount of the UC 
The variation amount of urea in the urea complexation was compared with the pure FFA (showed by 0 gram of urea in the graph of Fig.2). FFA mixture of palm oil hydrolysis contained $10 \%$ PUFA, and $90 \%$ SFA. After 20 grams of urea added, the PUFA concentration increase up to $96 \%$ and SFA decreased until 4\%. The complete analysis of PUFA and SFA concentration were shown in Table 3.

Table 3. Concentration of PUFA and SFA against Ratio of Urea : FFA in Complexation

\begin{tabular}{|c|c|c|c|c|}
\hline $\begin{array}{c}\text { Urea } \\
(\mathbf{g r a m})\end{array}$ & $\begin{array}{c}\text { FFA } \\
(\mathbf{g r a m})\end{array}$ & $\begin{array}{c}\text { Urea }: \text { FFA } \\
(\mathbf{m o l})\end{array}$ & $\begin{array}{c}\text { PUFA Concentration } \\
\mathbf{( \% )}\end{array}$ & $\begin{array}{c}\text { SFA Concentration } \\
\mathbf{( \% )}\end{array}$ \\
\hline 0 & 7 & & 10 & 90 \\
\hline 20 & 7 & $12.9: 1$ & 96 & 4 \\
\hline 40 & 7 & $25.9: 1$ & 96 & 3 \\
\hline 60 & 7 & $38.8: 1$ & 89 & 9 \\
\hline
\end{tabular}

In this research, the ratio of urea : FFA were made below, upper and exactly theoretically ratio as shown in Table 3. The ratio urea : FFA 25.9: 1 is the optimum condition proposed by Schlenk [6], so it was not possible to absorb more SFA molecule. The higher ratio $(38.8: 1)$ showed that excess of urea could decrease the PUFA concentration in the NUCF. According to the data, the complexation would be better if done at the ratio less or same $25.9: 1$.

According to a previous research[6], oleic acid (C18:1) as MUFA is an isomeric fatty acid compound with elaidic acid. Elaidic acid is an unsaturated fatty acid with trans isomer, while oleic acid is cis-isomer. Some fatty acids with trans-molecular isomers tend to form straight chains. This condition encourages the MUFA in trans-isomeric compounds to form an inclusion with urea. In contrast, PUFAs that have cis-isomers tend to form more bent bundles of the chain. This morphology makes PUFAs cannot easily form inclusions with urea. Due to its limited diameter, urea crystals tend to be filled by a straight chain compound. The kinked chain compound is pushed out by a straight chain compound, called "guest exchange"[7].

Palmitic acid has a straight-chain molecule. Linoleic acid has three double bonds, but their kinked bonding is relatively given straight chain, so it is eligible to form an inclusion with urea. However, linoleic acid is more difficult to form inclusions due to its bigger diameter. Number of double bonds provide the greater diameter of the molecule. Thus, it gives some difficulties for the unsaturated molecules to form an inclusion with urea[8].

\section{Conclusions}

This research concluded that PUFA concentration from palm oil could be enhanced with urea complexation. More amount of urea added to the complexation, the more saturated fatty acid (SFA) molecules adsorbed into urea crystals. The concentration of linoleic acid in cooking oil can be increased up to $96 \%$ by weight, given by the optimum ratio of urea/FFA between $12.9: 1-25.9: 1$.

\section{References}

[1] U. N. Wanasundara and F. Shahidi, "Concentration of omega 3-polyunsaturated fatty acids of seal blubber oil by urea complexation : optimization of reaction conditions," Food Chem., vol. 65, pp. 41-49, 1999.

[2] D. A. Setyawardhani, H. Sulistyo, W. B. Sediawan, and M. Fahrurrozi, "Separating poly-unsaturated fatty acids from vegetable oil using urea complexation: The crystallisation temperature effects," $J$. Eng. Sci. Technol., vol. 10, no. Spec.issue3, pp. 41-49, 2015.

[3] J. L. Guil-Guerrero and E.-H. Belarbi, "Purification process for cod liver oil polyunsaturated fatty acids," J. Am. Oil Chem. Soc., vol. 78, no. 5, pp. 477-484, 2001.

[4] N. A. Idris, S. K. Loh, and Y. M. Choo, "Urea fractionation of used palm oil methyl esters," J. Oil Palm Res., vol. 26, no. 3, pp. 226-231, 2014.

[5] D. G. Hayes, Y. C. Bengtsson, J. M. Van Alstine, and F. Setterwall, "Urea Complexation for the Rapid, Ecologically Responsible Fractionation of Fatty Acids from Seed Oil," J. Am. Oil Chem. Soc., vol. 75, no. 10, pp. 1403-1409, 1998.

The Concentration of Polyunsaturated Fatty Acid in Palm Oil by Urea Complexation (Dwi Ardiana Setyawardhani, Margono, Ardi Pratama, and Fermanditya Petratama) 
[6] H. Schlenk and R. Holman, "Separation and Stabilization of Fatty Acids by Urea Complexes," 1950.

[7] P. S. Kalsi, Organic Reaction and Their Mechanisms, 2nd ed. New Delhi: New Age International Publishers, 2000.

[8] D. A. Setyawardhani, H. Sulistyo, W. B. Sediawan, and M. Fahrurrozi, "Peranan Waktu Pengadukan Terhadap Karakteristik Kompleksasi Urea sebagai Sarana Pemisahan Asam Lemak Omega dari Minyak Nabati," J. Tek. Kim., vol. 16, no. 2, pp. 81-86, 2016. 